\title{
APPLIED COOPERATIVE LEARNING IN TEACHING DEVELOPMENTAL MATHEMATICS COURSES
}

\section{Qingxia Li}

Department of Mathematics and Computer Science Fisk University, Nashville, Tennessee, USA

\section{Xinyao Yang}

Department of Mathematics, University of Missouri, Columbia, MO

\section{Gloria Payne}

Department of Natural Sciences, Elizabeth City State University, Elizabeth City, NC

\begin{abstract}
This project integrates cooperative learning strategy in teaching developmental mathematics courses. This study uses a quasi-experimental non-equivalent control design comparing student's outcomes with and without implementing cooperative learning in these courses. The results of the data analysis shows that there is an increase in student's critical thinking ability, retention rate and the percentage of students obtaining A's and C's. This project is supported by Elizabeth City State University Minority Science and Engineering Improvement Program (Award Number: P120A110105).
\end{abstract}

Keywords: Cooperative Learning, Critical Thinking, Retention and Success Rate

\section{Introduction}

Cooperative learning techniques (Stenley and Siemund, 2011) are aimed at achieving the essential objectives in teaching college classes that may not be attained under the traditional teacher-directed classroom setting. However, collaborative learning techniques do not abandon the lecture, but rather use a combination of teacher-directed lectures and student-centered active learning techniques to supplement lectures.

This design requires much more active participation from students than passive lecture-only formats of the past required. This includes complex group exercises in which students apply course material to "real life" 
situations and/or to new problems. The term "collaborative learning" covers active learning experience which students solve the questions as groups rather than alone. In cooperative learning techniques, students work in groups and are assigned common quizzes as a group.

Salvin did a research review (Salvin, 1980) on classroom cooperative learning techniques in which students worked in small groups and received rewards or recognition based on their group performance. The review summarized the results of 28 primary field projects lasting at least 2 weeks, in which cooperative learning methods were used in elementary or secondary classrooms. The pattern of research findings supported the utility of cooperative learning methods in general for increasing student achievement, positive race relations in desegregated schools, mutual concern among students, student self-esteem, and other positive outcomes. The various cooperative learning methods were contrasted in terms of characteristics and outcomes.

The main of goal of this project is to get students to become interested in the world of mathematics and other related STEM courses. The activities designed for the program will provide students an opportunity to think logically and creatively on solving mathematics problems. The objectives of this proposal are: (1) to increase student's critical thinking ability through cooperative learning, (2) to encourage students to teach each other, (3) to get students to be prepared for upper level mathematics courses in their disciplines.

\section{Methodology}

Intermediate Algebra Course. Intermediate Algebra is designed to prepare students for Pre-calculus, Elementary Statistics, and other general education Mathematics courses. Intermediate Algebra is one of the fundamental and elementary courses for STEM majors. A student's score on the Mathematics Placement Exam will determine his or her placement in a mathematics course. Those students who score high enough to enroll in Calculus I are exempt from this three-hour math requirement. Otherwise, students cannot take advanced mathematics courses toward their degree without successfully completing this course. The course topics include: Linear equations and inequalities, graphing, linear systems, polynomials, factoring, and rational expressions, radicals, and quadratic equations.

Rationale. It is recognized that intermediate Algebra is ideally a level of mathematics maturity that can be achieved through a variety of topics and skills. It is not static, and it is changing and evolving along with the technology available to teach mathematics. It is a combination of computational skills, manipulative skills and critically thinking skills. Conceptual understandings and technical skill go hand in hand, each 
reinforcing the other. The teaching experience of the instructor showed that students from Intermediate Algebra courses don't understand the basic definitions of functions and algebraic expressions of fractions. Thus, students have difficulties when solving linear equations and inequalities. Furthermore, it causes more confusion in learning how to solve quadratic equations and inequalities, which are the main topics in this course. I used in-class quizzes, which focuses on the key topics that are necessary for this course, to identify the key information gaps. To promote conceptual reasoning, the instructor often uses an expanded emphasis on applications to promote an appreciation for mathematics in everyday life. However, the instructor cannot cover its applications in each discipline, so some students still look at mathematics simply as a group of formulas and numbers.

Design. This project uses a quasi-experimental non-equivalent control design comparing student outcomes in Intermediate Algebra courses before and after implementing the cooperative learning strategy. The independent variable will be Course Type (traditional baseline or experimental). Baseline measurement (before cooperative learning) took place in Fall 2011 and the Experimental measurement (after cooperative learning) was given during Fall 2012. A pretest and posttest on critical thinking was given at the beginning and the end of each semester.

In the Baseline condition (Fall 2011), the instructor lectured for three 50-minute periods per week in a traditional classroom setting. In Fall 2012, the Experimental condition contained a cooperative and student-centered active learning course design. This cooperative learning session involved reducing lecture time from 50 minutes to 20 minutes per class, adding cooperative learning workshops, adding group quizzes, adding technologybased independent learning materials to give students more practice time and feedback, and shifting instructional roles from information presentation to learning facilitation. The combination of teacher-led lectures and studentcentered problem solving workshops will enable faculty to have more oneto-one contact with students. During these periods, students will be assigned applied problems from Agriculture, Psychology, Biology, and other scientific disciplines. On the first day of class, students were divided into five groups according to the class roster and their majors. Each group had five or six students. At the end of each class, each group was assigned problems from core and challenging concepts. The group members helped each other to figure out the solutions to these questions. At the end of cooperative learning session, a quiz was given to the class and the average of the whole group was counted as extra credit.

Participants. The participants of this project are students from Intermediate Algebra courses in Fall 2011 and Fall $2012(N=110)$ The class 
in Fall 2011 serves as the control group under baseline condition and the class in Fall 2012 serves as the experimental group with treatment condition.

\section{Data Analysis of Fall 2011 and Fall 2012}

In the fall semester of 2011, 54 students were enrolled in my Intermediate Algebra class and 9 of them dropped the class during the semester. 42 completed the course with a letter grade and three of them received a passing grade for auditing the course. Their final grade are distributed as followings: A-5 students, B-12 students, C- 14 students, D-1 student and 10 students failed the class. The retention rate is $42 / 54=77.8 \%$ and the passing rate of the class is $32 / 42=76.2 \%$.

In the fall semester of 2012, 51 students were enrolled in my Intermediate Algebra class and 9 of them dropped the class during the semester. 45 completed the course with a letter grade. Their final grade are distributed as followings: A-8 students, B-5 students, C-20 students, D-1 student and 11 students failed the class. The retention rate is $45 / 51=88.23 \%$ and the passing rate is $34 / 45=75.6 \%$.

FIGURE 1: Retention Rate and Pass Rate of Fall 2011 and Fall 2012.

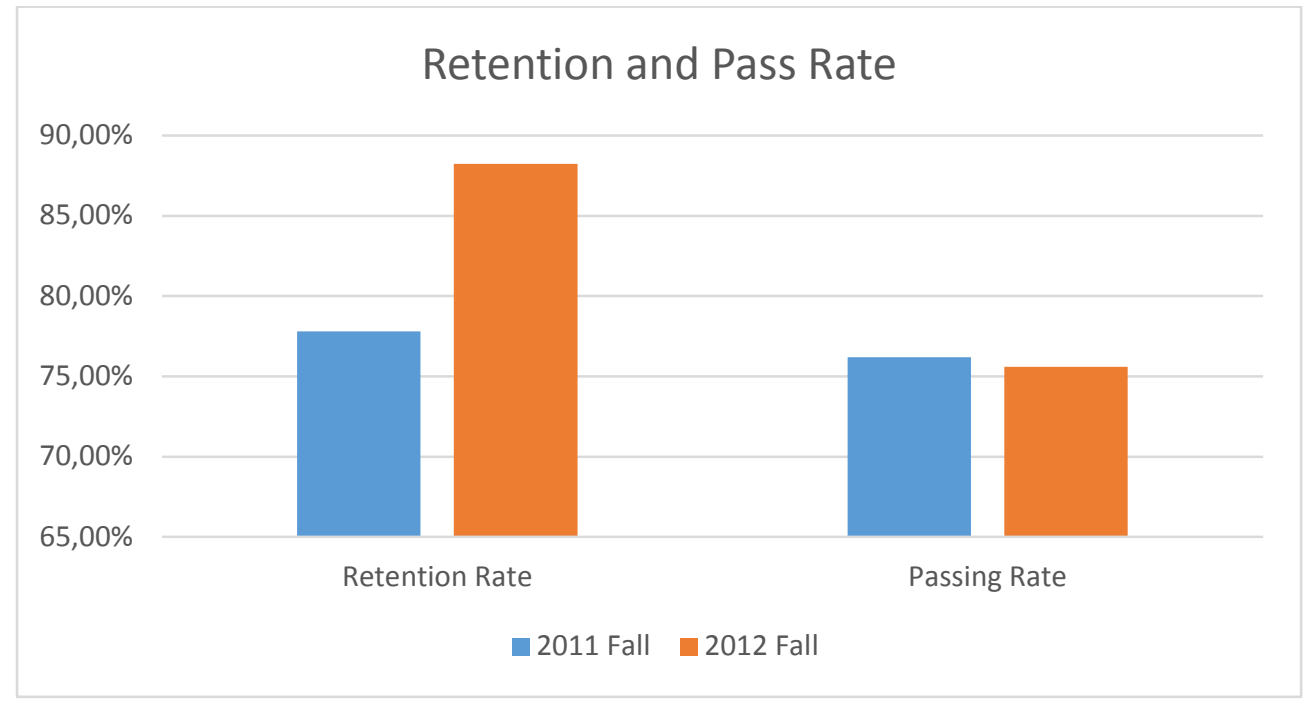


Figure 2: Grade distribution of Fall 2011 and Fall 2012.

\section{Grade distribution}

$50,00 \%$

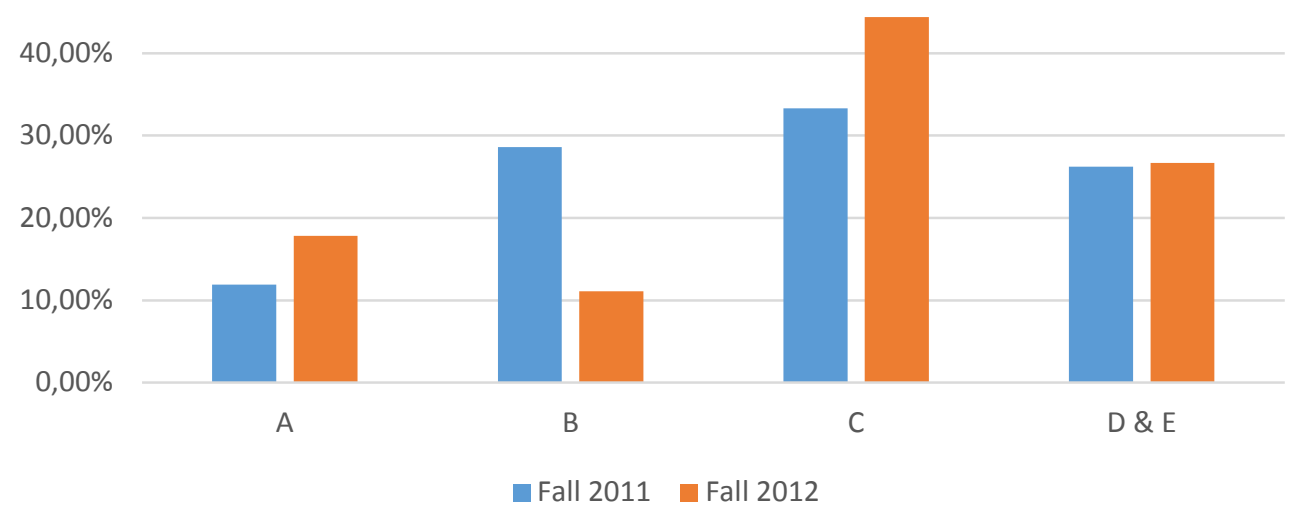

Figure 3: Descriptive statistics of Critical Thinking Pretest and Posttest in Fall 2011 and 2012.

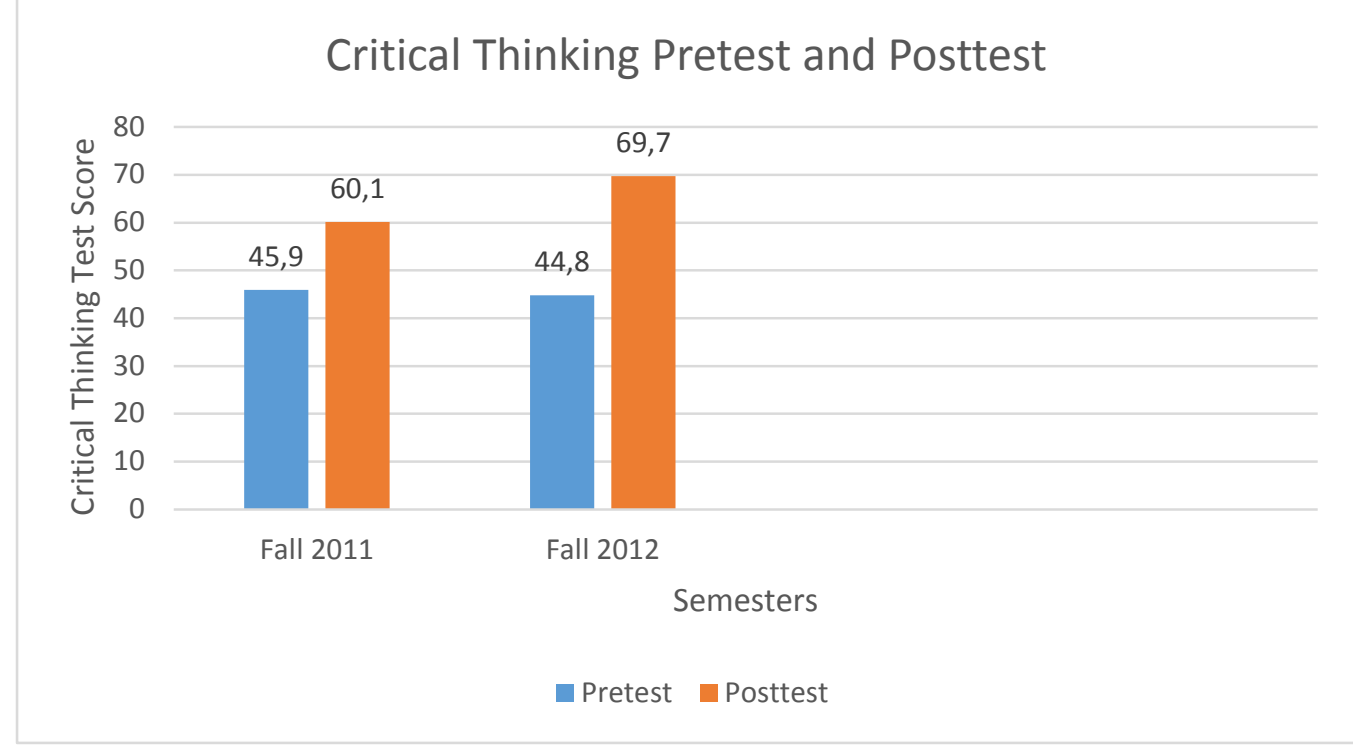

Data Assessment. Comparing the results from Figure 1 and Figure 2, the retention rate had a $10 \%$ increase and the passing rate remained relatively stable under the new teaching technique. The newly developed teaching technique did show great improvement in retaining the students, but it did not show great improvement in passing. The students who obtained A's and C's had a great increase, but it has a decrease in B's. In figure 3, students had an average of $31 \%$ increase in critical thinking posttest compared with pretest in Fall 2011, while students had an 55\% increase in Fall 2012. 


\section{Conclusion}

The positive outcome of this project was the great increase in student's critical thinking ability, retention rate and the great increase of students obtaining A's and C's in this course. It showed that cooperative learning did promote students to think critically and stay in the class until the end of this course. Students, especially high achieving students (students who obtained A's) and relatively low achieving students (students who struggled to pass the course), obtained the most benefits from helping other students and learning from their classmates. However, the pass rate of the course did not show an increase and there was a decrease of students obtaining B's in the course.

\section{References:}

Stenley, J. and Siemund, P. (2011). Roundtable as Cooperative Learning Technique, English Language and Linguistics, 18 (01), pp 40-45.

Lyman, F. T. (1981). The responsive classroom discussion: The inclusion of all students. In A. Anderson (Ed.), Mainstreaming Digest (pp. 109-113). College Park:University of Maryland Press.

Slavin, R. (1980) Cooperative Learning, Review of Educational Research, Volume 50, no.2, 315-342. 